\title{
Context and Trade-offs in Family Medicine
}

\author{
Dean A. Seehusen, MD, MPH, Marjorie A. Bowman, MD, MPA, \\ and Anne Victoria Neale, PhD, $M P H$
}

This issue contains several articles that highlight the effect of context and tradeoffs encountered in the practice of family medicine. Some articles demonstrate how context affects the implementation of the patient-centered medical home model, the community risk of a measles outbreak, the rate of complementary and alternative medicine among different generations, and the number of family physicians primarily providing urgent and emergent care in a region. Tradeoffs are explored in articles that look at how electronic medical record use has changed the composition of workload in primary care and how the burgeoning number of clinical guidelines affects the choices made by family physicians. A look at diabetic patients' perceptions of their risk of negative outcomes reveals an interesting pattern of underestimation of the risk of death. Patients with chronic mental disorders are at risk of having significant difficulties in the workplace, which may place a heavy cost on the individual and society. An interesting retrospective study found that it takes a surprising amount of replacement therapy to correct vitamin D deficiency. (J Am Board Fam Med 2014;27:433-436.)

\section{Context and Trade-offs}

Family physicians regularly take context into consideration. We learn early in our training that no 2 clinical situations, no 2 patients are exactly the same. Sex, age, cultural background, social circumstances, sexual preference, and a host of other factors can affect patient care in a profound way. Family physicians also understand inherently that trade-offs are a routine function of medical practice. Life-saving medications often cause unwanted side effects. Cancer screening may lead to incidental findings that lead to unrewarding testing or treatment. If you administer enough routine vaccinations, you may encounter an adverse event. This issue of the Fournal of the American Board of Family Medicine contains several articles that highlight the effect of context and trade-offs encountered in the practice of family medicine.

For example, Solberg et $\mathrm{al}^{1}$ demonstrate that context matters for patient-centered medical home (PCMH) implementation. In this study, using a survey of 120 Minnesota clinics that recently undertook practice transformation to become certified as medical homes, the authors attempted to find common change characteristics and associate

Conflict of interest: The authors are editors of the $7 A B F M$. them to improved clinical performance measures. While some common change themes emerged, each practice had specific local factors that were influential, and the changes could not be attributed to performance outcomes. As suspected, each practice must take a unique path to PCMH certification based on multiple local factors; there is no proven formula for successful PCMH implementation.

A trade-off associated with PCMH implementation involves the type of patient-provider interactions. With the increasing emphasis on non-faceto-face interactions, the composition of workload in primary care is changing. Arndt et $\mathrm{al}^{2}$ use both survey results and electronic health record data to evaluate the contribution of these non-face-to-face patient-provider interactions on overall workload. The authors conclude that non-face-to-face patient care activities contribute significantly to overall provider workload. The percentage of workload attributable to these interactions will only increase over time as technology makes non-face-to-face encounters more practical and productivity demands encourage these types of encounters. The results of this study have important implications for workforce planning, productivity measurement, and physician reimbursement reform.

Peterson et $\mathrm{al}^{3}$ report that $6.7 \%$ of US family physicians spend at least $80 \%$ of their time provid- 
ing emergency or urgent care. The percentage of family physicians providing primarily emergency or urgent care is higher in rural regions, topping out at $>10 \%$. In the context of sparsely populated areas, family medicine, urgent care, and emergency care increasingly meld into each other. The authors point out that these figures need to be factored into any model of the US physician workforce distribution. Klink ${ }^{4}$ provides a well-thought-out exploration of the implications of these findings.

An interesting study from Wolff and Madlon$\mathrm{Kay}^{5}$ demonstrates how cultural context can have a significant effect on preventive services uptake, which, in turn, can affect the health of an entire community. In response to a 2011 outbreak of measles in Minnesota, parents in Minneapolis were surveyed about vaccine beliefs. Among Somali parents, $22 \%$ reported refusing measles-mumps-rubella vaccinations for their children-a significantly higher refusal rate than that of non-Somali parents (odds ratio, 4.6; 95\% confidence interval, 1.218.0). Somali parents also were more likely to report the belief that vaccines can cause autism $(35 \%$ vs $8 \% ; P=.02)$. These results point to an opportunity for focused community engagement and education to prevent future measles outbreaks.

Ho et $\mathrm{al}^{6}$ studied how the context of generational differences affects the use of complementary and alternative medicine (CAM). The Baby Boomer generation (born 1946-1964) were more likely to have used CAM in the past 12 months compared with the Silent Generation (born 1925-1945) (43.1\% vs $36.4 \% ; P<.001)$, despite being younger and healthier. Those with chronic diseases, and especially those with chronic pain, were the most likely to have used CAM. As the Baby Boomer generation ages, their use of CAM is likely to increase, making the ability to communicate with patients about CAM an imperative skill for family physicians.

In a thought-provoking commentary, Ganiats and Kempster $^{7}$ point out the uncomfortable fact that implementation of one set of clinical guidelines often necessitates not implementing another set of guidelines. Physicians faced with limited time during clinical visits have to choose which guidelines they will implement and which they will pass over. Unfortunately, physicians are forced to calculate these tradeoffs without an evidence base because reliable information to compare the effect of various guidelines on patient outcomes is still needed. Culpepper ${ }^{8}$ provides an equally thought- provoking counterpoint to these thoughts; he does not share the view that care is de facto rationed when more clinical guidelines are applicable than there is time to address those required.

Atlas et $\mathrm{al}^{9}$ report a study in which primary care providers (PCPs) were incorporated into an information technology-based population management strategy that automatically generated reminder letters to encourage timely cancer screening. After 1 year, cancer screening rates were similar in the study and control arms, but the number of reminder letters sent was reduced by nearly onequarter in the arm that included PCPs. Providers in the intervention arm reported improved satisfaction and felt their time for cancer screening was more efficiently used. It is important to consider that other possible outcomes of this approach were not addressed in this study. Patient satisfaction, overscreening rates, and even clinical outcomes may be improved by including PCPs in population management strategies. The obvious trade-off here is that PCPs then spend less time performing other tasks. Further study is warranted to evaluate the overall impact of this model.

\section{Groundbreaking Studies}

The last time a patient asked you for an excuse from work, did you consider the possibility that the patient may be suffering from workplace phobia? Probably not, since this diagnosis has received relatively little attention to date. Muschalla and Linden ${ }^{10}$ present a study of primary care patients with chronic mental disorders, revealing that workplace phobia, and other workplace issues, are relatively frequent. In a German primary care population, slightly $>10 \%$ of patients with chronic mental disorders met criteria for workplace phobia. The authors point out that this extrapolates to around $3 \%$ of all primary care patients. Since workplace phobia leads to an increase in lost work days, the personal and societal costs of this condition could be enormous. Expect to read more about this phenomenon in the future.

In an interesting retrospective study of vitamin D replacement, Singh and Bonham ${ }^{11}$ document that increasing serum 25-hydroxyvitamin D concentrations are typically associated with much higher doses of replacement therapy than are often prescribed based on many current guidelines. The authors further used their data to develop equations to predict how much vitamin D3 replacement is 
needed based on 25-hydroxyvitamin D concentrations for both ambulatory and nursing home patient characteristics. These equations suggest that most patients require approximately $5000 \mathrm{IU} /$ day to correct their deficiency and need $>2000$ IU/day as a maintenance dose. These doses are similar to newer guidelines from the Endocrine Society. ${ }^{12}$ While these findings will be surprising to many, they are compelling because the study was conducted under real-world circumstances with a large volume of patients.

\section{Other Interesting Reading}

Saver et $\mathrm{al}^{13}$ evaluated patients' ability to estimate and rank their personal risks of various outcomes from diabetes. In this study, nearly all patients underestimated their personal risk of serious diabetic complications, especially death. Death was the most adverse event for these patients but was almost universally ranked as the least likely by the patients. Even after being explicitly educated, participants tended to dramatically underestimate their risks, relying instead on anecdotal information such as family history and "self-knowledge." The fascinating findings from this mixed methods study underscore the daily challenges family physicians face when educating patients about personal risk.

Meyers et $\mathrm{al}^{14}$ found systematic screening of an uninsured, urban, mostly African American population resulted in an increased rate of diagnosis of depression. The study further found that treatment improved 9-item Patient Health Questionnaire scores at 24 weeks. These findings are similar to those reported from other populations. An unexpected conclusion of the study is that the addition of psychotherapy, education, or both to usual care did not result in greater reductions in score than usual care alone.

This $7 A B F M$ issue also offers 2 excellent clinical reviews. In the first, Cave and Atkinson ${ }^{15}$ review the approach to diagnosing asthma in preschool children, including highlights from applicable clinical guidelines. The second review provides welcome clarity to the potentially confusing clinical problem of bleeding disorders in adults. ${ }^{16}$

Finally, we also have 2 interesting clinical cases, one of an active-duty soldier with renal failure after exposure to a readily available, over-the-counter dietary supplement ${ }^{17}$ and another describing the case of a very unusual presentation of atrial fibrillation. ${ }^{18}$ Editorial board member Adam Goldstein also shares poetry. ${ }^{19}$

\section{References}

1. Solberg LI, Crain AL, Tillema J, et al. Challenges of medical home transformation reported by 118 patient-centered medical home (PCMH) leaders. J Am Board Fam Med 2014;27:449-57.

2. Arndt B, Tuan W-J, White J, Schumacher J. Panel workload assessment in US primary care: accounting for routine non-face-to-face panel management activities. J Am Board Fam Med 2014;27:530-7.

3. Petterson S, Peterson L, Phillips RL, et al. One in fifteen family physicians principally provide emergency or urgent care. J Am Board Fam Med 2014; 27:447-8.

4. Klink K. Urgent and emergency family physicians in rural communities. J Am Board Fam Med 2014;27: 444-6.

5. Wolff ER, Madlon-Kay DJ. Childhood vaccine beliefs reported by Somali and non-Somali parents. J Am Board Fam Med 2014;27:458-64.

6. Ho TF, Rowland-Seymour A, Frankel ES, Li SQ, Mao JJ. Generational differences in complementary and alternative medicine (CAM) use in the context of chronic diseases and pain: baby boomers versus the silent generation. J Am Board Fam Med 2014;27:465-73.

7. Ganiats TG, Kempster JA. Rationing on the fly: the opportunity cost of clinical guidelines. J Am Board Fam Med 2014;27:439-41.

8. Culpepper L. Counterpoint: rationing on the fly: the opportunity cost of clinical guidelines. J Am Board Fam Med 2014;27:441-3.

9. Atlas SJ, Zai AH, Ashburner JM, et al. Non-visit-based cancer screening using a novel population management system. J Am Board Fam Med 2014;27:474-85.

10. Muschalla B, Linden M. Workplace phobia, workplace problems, and work ability among primary care patients with chronic mental disorders. J Am Board Fam Med 2014;27:486-94.

11. Singh G, Bonham AJ. A predictive equation to guide vitamin D replacement dose in patients. J Am Board Fam Med 2014;27:495-509.

12. The Endocrine Society. Evaluation, treatment, and prevention of Vitamin D deficiency: An Endocrine Society clinical practice guideline. Available at: https://www.endocrine.org/ /media/ endosociety/Files/Publications/Clinical\%20Practice $\% 20$ Guidelines/FINAL-Standalone-Vitamin-DGuideline.pdf. Accessed May 29, 2014.

13. Saver BG, Mazor KM, Hargraves JL, Hayes M. Inaccurate risk perceptions and individualized risk estimates by patients with type 2 diabetes. J Am Board Fam Med 2014;27:510-9.

14. Meyers MA, Groh CJ, Binienda J. Depression screening and treatment in uninsured urban patients. J Am Board Fam Med 2014;27:520-9.

15. Cave AJ, Atkinson LL. Asthma in preschool children: a review of the diagnostic challenges. J Am Board Fam Med 2014;27:538-48. 
16. Kruse-Jarres R, Singleton TC, Leissinger CA. Identification and basic management of bleeding disorders in adults. J Am Board Fam Med 2014;27:549-64.

17. Siano KA. Renal failure in a soldier taking N.O.Xplode. J Am Board Fam Med 2014;27:565-9.
18. Thomassin SS, Zinn S. Atrial fibrillation diagnosed through sensory complaints. J Am Board Fam Med 2014;27:570-4.

19. Goldstein A. Poetry in a pill. J Am Board Fam Med 2014;27:575. 